\title{
COMPARATIVE STUDY OF THE MICROPORE DEVELOPMENT ON PHYSICAL ACTIVATION OF CARBON FIBERS FROM COAL TAR AND PETROLEUM PITCHES
}

\author{
E. Vilaplana-Ortego, J. A. Maciá-Agulló, J. Alcañiz-Monge*, \\ D. Cazorla-Amorós and A. Linares-Solano.
}

Dpto. Química Inorgánica, Universidad de Alicante, E-03080 Alicante, Spain.

\begin{abstract}
.
Activated Carbon Fibres (ACFs) have been successfully prepared with a remarkable development of porosity, from four isotropic coal tar pitches and four isotropic petroleum pitches. Special care has been put to make the activation process at similar activation rate in order to have a better comparison of the different precursors used. The micropore volumes of petroleum pitches-derived ACFs are higher than those obtained from coal tar pitches under similar activation yields. The resultant ACFs present interesting textural properties: they are essentially microporous materials, with a high adsorption capacity which increases linearly with the burn-off. It has been observed, independently of the pitch precursor used, that the micropore volume is a function of the degree of activation, being, in all the cases, quite similar for a given activation degree if a comprehensive weight loss is considered (carbonization lost and degree of activation).
\end{abstract}

Keywords: Pitch; Carbon fibres; Activation; Microporosity.

*Corresponding author. Fax; +34 965903454 E-mail address: jalcaniz@ua.es (Juan AlcañizMonge) 


\section{INTRODUCTION.}

The preparation of activated carbon fibres (ACFs) from pitch-derived carbon fibres (CFs) is still of interest due to their huge number of applications, such as in air filters, masks, waste water purification systems, and so on [1]. These materials present interesting advantages compared with conventional activated carbons (ACs) (powdered or granular) since they exhibit higher adsorption capacities and higher adsorption/desorption kinetics. Their main disadvantage compared with conventional ACs is their cost. In this sense, the search of low- cost precursors and preparation methods is still required [2-5].

The preparation of ACFs from very different precursors has been extensively studied in order to, among other reasons, select cheap precursors. Thus, for example, rayon [6-8], nomex [9], phenolic resin [10] and pitches [11-15] were tested. From the point of view of cost reduction, in addition to the precursor cost (low in the case of pitches), the carbonisation yield is also important. Thus, it is interesting to point out that the carbonization yields of the CFs from pitches, in the range of $70-85 \mathrm{wt} \%$, are much higher than those for other precursors $[14,15]$. Regarding the preparation of CFs from pitches, most of the published studies use petroleum pitches as CFs precursors, while the use of CFs derived from coal tar pitches is scarce [16].

In the present work we compare the textural characteristics of the ACFs prepared from four coal tar pitches and from four petroleum pitches obtained under similar activation rate conditions, as well as their activation yields, to get insights about their suitability as ACF precursors. 


\section{EXPERIMENTAL.}

\subsection{Materials}

In this study eight types of CFs have been prepared from eight different pitches. Four of them have been obtained after the heat treatment of commercial coal tar pitches from different industries (A and B come from Bilbaina de Alquitranes and C and D from Industrial Química del Nalón). Some details about these precursors were previously reported [14]. The other four CFs precursor pitches were obtained from four petroleum pitches. Pitches Q, R, and V have been synthesised by vacuum distillation in laboratory, and the last one $(\mathrm{P})$ is a commercial petroleum pitch CF precursor (Showa Oil Co.). Table 1 summarises some properties of the treated pitches.

\subsection{Preparation of carbon fibers.}

Details of the preparation conditions of the carbon fibers can be found elsewhere [1416]. In summary, the preparation process includes the following steps: a) treatment to transform the pitches into spinnable pitches, b) pitch spinning process, c) stabilization process of the pitch fibers, and d) carbonization process of the stabilized pitch fibers.

The raw coal tar pitches were submitted to the following treatments in order to make them suitable for CF preparation: a) the infusible matter was removed by filtration of the fraction of the pitch insoluble in quinoline, b) the filtrated pitch was subjected to a heat treatment in air (airblowing) at different temperatures (between $623-773 \mathrm{~K}$ ) and times (no longer than 2.5 hours) and c) petroleum pitches were submitted at heat treatment in vacuum distillation at 473$523 \mathrm{~K}$.

A monofilament spinning apparatus was used to obtain the pitch fibers. The diameter of the nozzle of the spinning apparatus, that determines the diameter of the fibers, was $1.5 \mathrm{~mm}$. The 
spinning temperature was $50-100 \mathrm{~K}$ higher than the softening point (SP) of the spinnable pitch. After that, the pitch fibers obtained were stabilized in a flow of air $(500 \mathrm{ml} / \mathrm{min}, \mathrm{STP})$ using the following stabilization programme that lasted 6 hours:

(1) Heating at $5 \mathrm{~K} \mathrm{~min}^{-1}$ to $403 \mathrm{~K}$.

(2) Heating at $1 \mathrm{~K} \mathrm{~min}^{-1}$ to $493 \mathrm{~K}$, maintaining this temperature for 1 hour.

(3) Heating at $1 \mathrm{~K} \mathrm{~min}^{-1}$ to $573 \mathrm{~K}$, maintaining this temperature for 2 hours.

In the carbonization stage, the stabilized pitch fibers were heated at $10 \mathrm{~K} \mathrm{~min}^{-1}$ to $1273 \mathrm{~K}$ in a $\mathrm{N}_{2}$, atmosphere (80 ml/min, STP), maintaining this temperature for 30 minutes. The CFs yield was determined taking into account the original weight of the pitch fibers and the final weight of the carbonised pitch fibers. The nomenclature for the resulting eight CFs includes the pristine pitch letter.

\subsection{Preparation of activated carbon fibers}

The activation on the different $\mathrm{CFs}$ was performed using $\mathrm{CO}_{2}$ as an activating agent. In order to carry out their activation in similar conditions of initial reactivity, the activation temperature was selected after reactivity experiments conducted in microbalance equipment (Setaram DSC-92). Thus, the activation of CFs from coal tar pitches was performed at $1140 \mathrm{~K}$, and $1160 \mathrm{~K}$ was the temperature selected for the CFs prepared from the petroleum pitches. The activation experiments were carried out in a horizontal furnace. The samples were heated at 5 $\mathrm{K} / \mathrm{min}$ in nitrogen until the selected activation temperature was reached (1140 and $1160 \mathrm{~K})$. Then the gas was changed to $\mathrm{CO}_{2}$ with a flow of $80 \mathrm{ml} / \mathrm{min}$. The selected activation temperature was held for a certain period of time to reach the desired burn-off (BO). The ACFs were cooled in nitrogen until room temperature was reached. Then, the samples were weighed to assess the degree of activation which is indicated after the nomenclature. 


\subsection{Porous texture characterization}

The porous texture of the obtained ACFs and their precursor CF was characterised by physical adsorption of gases (i.e. $\mathrm{N}_{2}$ at $77 \mathrm{~K}$ and $\mathrm{CO}_{2}$ at $273 \mathrm{~K}$ ) in two volumetric equipments (Autosorb-6B and Autosorb-6, respectively), and it was also characterised by mercury porosimetry (Carlo Erba). For comparative purposes, two well-known commercially available ACF from Osaka Gas Co. (samples A15 and A20) have been analysed. Before the adsorption tests, samples were outgassed at $523 \mathrm{~K}$ under vacuum for 4 hours. Apparent surface area was determined by applying the BET [17] (Brunauer-Emmett-Teller) equation, and the micropore volume by the DR (Dubinin-Radushkevich) method [18].

\section{RESULTS AND DISCUSSION.}

\section{1.- ACFs Preparation.}

As stated in the experimental section, the activation of the different CFs was performed at similar initial reactivity conditions. In this sense, it was observed by TG experiments that the CFs from coal tar pitch present higher reactivity than the petroleum pitch ones. Therefore, the formers were activated at a temperature $20 \mathrm{~K}$ lower than the petroleum pitch CFs. These differences in reactivity could be attributed to their carbonisation process and temperature differences and their subsequent effect on the resulting CF structure [19]. Thus, it was observed that the yields of the CFs prepared from petroleum pitches $(60-70 \mathrm{wt} \%)$ are lower than for coal tar pitch derived CFs $(85 \%)$. These differences in CF yield seem to be related to the higher content of alkyl groups of the petroleum pitches CFs [20]. As a result of the rupture of these alkyl groups, higher numbers of radicals are generated and their subsequent condensation reactions could lead to a higher perfection of the graphene layers [21], rendering to a reactivity 
of the petroleum pitch CFs lower than that of the coal tar pitch CFs.

Figure 1 shows the evolution of the burn-off percentage versus the time of activation for each prepared CFs. In general, it can be seen that our purpose of preparing ACFs from different pitches at similar initial activation rates (assessed by thermogravimetric experiments), has been reached, with the two selected activation temperatures (1140 and $1160 \mathrm{~K})$. Nevertheless, it must be pointed that, although the initial activation rate of all $\mathrm{CFs}$ is similar, the $\mathrm{BO}$ evolution is different for each pitch precursor CF. Thus, there are samples (i.e. D) which show a higher BO than others for comparable activation times in all range of BO. Other samples that initially show a high BO (i.e. P) present, for long activation times, a different behaviour. Also, there are samples (i.e., Q and R) that initially show low BO and, for longer times, show a higher BO. All these observations must be related with differences in the microstructures that are developed from pitches of different chemical compositions.

\section{2.- Characteristics of the prepared ACFs.}

Figures 2 to 4 present the $\mathrm{N}_{2}$ adsorption isotherms obtained at $77 \mathrm{~K}$ for some representative examples of the prepared ACFs. The important details of these isotherms are: the magnitude of adsorption in the near-plateau, the sharpness of the knee and the relative pressure for which the linear section begins, and the slope of the linear section. As it can be observed from the figures (2 to 4), the adsorption capacity of the ACFs increases with the degree of activation, reaching high adsorption capacity values. All the isotherms are type I following the IUPAC classification [22], indicative of the microporous character of the ACFs prepared. Interestingly, as shown in Figures 2 and 3, even at activation degrees of $50 \%$, all the isotherms

are parallel to the $\mathrm{x}$ axis at $\mathrm{P} / \mathrm{Po}>0.3$, confirming the absence of mesoporosity and 
macroporosity in the samples. Clearly, the linear region of the isotherms begins at higher relative pressures in Fig.4 than in Figs. 2 and 3, being the most pronounced one that for sample CFV90. A closer look reveals that the slopes of the linear sections are slightly larger in Fig.4 than in Fig.3, being the highest for sample CFV90. All these observations indicate a widening of the microporosity without any remarkable mesoporosity development. The development of a wider microporosity as the BO increases can also be appreciated from the analysis of the sharpness of the isotherm knees. For instance, the knee for CFB32 (Fig.2) is evidently sharper than that for CFA37, indicating that the micropores in CFA37 have larger width than in the case of CFB32. This is even more remarkable for sample CFV90 (Figure 4), which shows a more open knee denoting the existence of a wider microporosity.

The $\mathrm{N}_{2}$ adsorption isotherms of the two commercial samples used, A15 and A20, are plotted in Figure 3 and 4, respectively. Although the activation degree of these two samples is not reported by the company, their isotherms have been plotted in Figure 3 and Figure 4 according to their shapes. A15 behaves as samples from Figure 2 and 3, whereas A20 behaves as those in Figure 4. The porous texture of all these materials contrasts with the results obtained by other authors, where the ACFs have appreciable mesoporosity values (30\% of the total volume) for samples with 60-65 wt \% burn-offs, even when they use coal tar pitches [23], liquid carbon extracts [24] or petroleum pitches [13] as raw materials.

Tables 2 and 3 collect the porous texture characterisation data derived from the $\mathrm{N}_{2}$ and $\mathrm{CO}_{2}$ adsorption isotherms. It is important to remark that the microporosity volume obtained from the $\mathrm{N}_{2}$ adsorption corresponds to the whole range of microporosity (pore size up to $2 \mathrm{~nm}$ ), while the $\mathrm{CO}_{2}$ adsorption only provides information about narrow microporosity $(<0.7 \mathrm{~nm})$ [25-27].

Firstly, the differences found in the porosity of the CF prepared from the different 
pitches must be noticed. Thus, in the case of coal tar pitches coming from different industries, appreciable differences are found. CFs obtained from A and B pitches have an important initial narrow microporosity, potentially interesting to use them as carbon molecular sieves (CMS), while CFs prepared from pitches $\mathrm{C}$ and $\mathrm{D}$ have negligible microporosity. Regarding the $\mathrm{CF}$ produced from petroleum pitches, all of them present an important narrow microporosity volume $\left(\mathrm{VCO}_{2}\right)$. The differences among them can be detected in the micropore size distribution, which can be deduced when comparing the micropore volume from $\mathrm{N}_{2}$ and the data for $\mathrm{CO}_{2}$ adsorption. In this sense, there exist two types of CFs derived from different petroleum pitches; pitches $\mathrm{P}$ and $\mathrm{V}$ produce $\mathrm{CFs}$ with microporosity only accessible to $\mathrm{CO}_{2}$ (as in the case of some coal tar pitches), while the rest of the petroleum pitches produce CFs that present considerable microporosity accessible to $\mathrm{N}_{2}$ suggesting a wider porosity. In general, the results obtained show that CFs obtained from petroleum pitches present higher microporosity than the coal tar pitch ones.

Results collected in the Tables 2 and 3, indicate that the initial porosity of the CFs can have an effect on the development of porosity of the ACFs, and especially on the low burn-off ACFs. Thus, it can be observed that the CFs with lower narrow microporosity (CF C and D) produce, at lower and comparable BOs, ACFs with apparent surface area and porosity quite small compared to the CFs with high initial porosity (ie. CFD25 has a $\mathrm{VN}_{2}$ of $0.2 \mathrm{~cm}^{3} / \mathrm{g}$ while CFR20 shows $0.39 \mathrm{~cm}^{3} / \mathrm{g}$ ). Additionally, the generation of narrow microporosity (pore size $<0.7$ $\mathrm{nm}$ ) can be appreciated up to BOs close to $40-50 \mathrm{wt} \%$, as indicated by the increase on the $\mathrm{VCO}_{2}$ and the beginning of the isotherms (see Figure 2 and 3). In a similar way, the widening of porosity can be clearly observed at higher BOs, and it is reflected on the generation of supermicroporosity $\left(\mathrm{V}_{\mathrm{N} 2}>\mathrm{V}_{\mathrm{CO} 2} ; 0.7 \mathrm{~nm}<\right.$ pore size $\left.<2 \mathrm{~nm}\right)$ and in the knee of the isotherms (Figure 4). It must be remarked that, in general, the results obtained show that we have prepared 
ACFs with high surface areas and high micropore volumes, which are comparable to the wellknown available commercial ACFs (A15, A20).

\subsection{Coal tar pitch ACFs vs petroleum pitch ACFs}

To compare ACFs prepared from coal tar pitches with the ACFs derived from petroleum pitches we present Figure 5, which shows the evolution of the micropore volumes (obtained from the $\mathrm{N}_{2}$ adsorption data (Figure 5a) and from $\mathrm{CO}_{2}$ adsorption data (Figure 5b)) versus the burn-off percentage for all the ACF prepared in this study.

As it can be seen in these Figures, the micropore volume (more remarkably the narrow micropores showed in the Figure 5b) of ACFs prepared from petroleum pitches is always higher than that for coal tar pitches derived ACFs in the range of burn-off analysed This observation is important because the development of porosity during the activation depends on the starting porosity of the pristine material, which is higher for the CFs obtained from petroleum pitches.

As mentioned before, the preparation yields of $\mathrm{CFs}$ from coal tar pitches are higher than for petroleum pitches, about $85 \mathrm{wt} \%$ and $60-70 \mathrm{wt} \%$, respectively. To take into account these differences, comprehensive yields (carbonization plus activation) have to be considered. Figure 6 shows the micropore volume (assessed by $\mathrm{N}_{2}$ adsorption) versus the comprehensive weight loss. Interestingly, the micropore volume depends on the comprehensive yield and not on the origin of the pitch precursor used. Thus, we can see that, for a given comprehensive yield, the microporosity for both petroleum and coal tar pitches are quite similar.

On the other hand, it must be mentioned that a relatively high comprehensive weight loss 
(>30 wt \%) is required to generate microporosity accessible to $\mathrm{N}_{2}$ at $77 \mathrm{~K}$. This fact is observed independently of the pitch precursor used to prepare the CFs. The reason why this microporosity is not detected can be related with diffusional problems of the $\mathrm{N}_{2}$ molecules at $77 \mathrm{~K}$ inside the narrow microporosity (pore size $<0.7 \mathrm{~nm}$ ) [25-27]. This problem would not occur for $\mathrm{CO}_{2}$ adsorption at $273 \mathrm{~K}$.

Figure 7 plots the narrow micropore volume, assessed by $\mathrm{CO}_{2}$ adsorption at $273 \mathrm{~K}$, versus the comprehensive weight loss (wt \%). It can be seen that in this case, samples with low comprehensive weight losses show microporosity accessible to $\mathrm{CO}_{2}$ at $273 \mathrm{~K}$. This fact agrees with the non diffusional limitation that $\mathrm{CO}_{2}$ adsorption at $273 \mathrm{~K}$ shows in the narrower micropores [25-27]. On the other hand, contrarily to Figure 5, ACFs derived from petroleum pitches behave differently (see marked samples in Figure 7) at high burn-off levels, presenting higher proportion of narrow micropores. Considering that all the samples have been prepared in similar activation conditions and their total micropore volumes are similar (see Figure 6), the different development (at high burn-off levels) of narrow microporosity in the pitches of different origin must be related to a different carbonaceous microstructure created during the carbonisation process of the pitch fibres and their subsequent activation process. This observation suggests that the chemical composition of the parent pitches plays an important role on the development of the carbonaceous microstructure. It is well known in the literature [29] that coal tar pitches show a higher degree of aromaticity than petroleum pitches, which is related with their higher content on polycyclic aromatic hydrocarbons $(\mathrm{PAH})$ of a high number of aromatic rings [30]. Petroleum pitches shows an important content in aliphatic hydrocarbon chains and a lower condensation degree on their aromatic rings. Hence, the carbonisation of the petroleum pitches produces a less condensed carbonaceous microstructure than coal tar pitches. The carbonisation of the former generates smaller graphite microcrystals, whose activation, even 
at high burn-off, continues to develop narrow microporosity, contrarily to coal tar pitches, which suffer a widening process of the narrow microporosity at high burn-off.

\section{CONCLUSIONS.}

ACFs have been successfully prepared with a remarkable development of porosity from four isotropic coal tar pitches and four petroleum pitches. The resultant ACFs present interesting textural properties: they are essentially microporous materials, with high adsorption capacity which increases linearly with the burn-off. Their textural properties are comparable independently of origin of the precursor used and are similar to those for available commercial ACFs.

It has been observed that, depending on the parent pitch (coal tar pitch or petroleum pith), CFs with significant differences in the initial porosity can be obtained. It has been observed, for both types of pitch precursors, that the micropore volume is a function of the degree of activation, being, in all the cases, quite similar for a given activation degree if a comprehensive weight loss is considered (carbonization lost and degree of activation). Regarding their narrow microporosity, CFs and ACFs from petroleum pitches contain a higher proportion of these narrow micropores indicating the influence of the different carbonaceous microstructure generated during the carbonisation process of the pitch fibres precursor (coal and petroleum).

\section{Acknowledgements.}


The authors thank the MEC and FEDER (CTQ2006-08958) and GV (GV/2007/144 and ARVIV/2007/063) for the financial support.

\section{5.- REFERENCES.}

[1]. J. B. Donnet, S. Rebouillat, T.K. Wang, J.C.M. Peng. Carbon Fibers, $3^{\text {rd }}$ Edition, Marcel Dekker, New York, 1998.

[2]. M. Suzuki. Carbon 32 (1994) 577.

[3]. E. Vilaplana-Ortego, J. Alcañiz-Monge, D. Cazorla-Amorós, A. Linares-Solano. Fuel Processing Technology 88 (2007) 265.

[4]. E. Vilaplana-Ortego, J. Alcañiz-Monge, D. Cazorla-Amorós, A. Linares-Solano. Carbon $41(2003) 1001$.

[5]. S. H. Park, C. Kim, Y. O. Choi, K. S. Yang. Carbon 41 (2003) 2653.

[6]. R. N. Mcnair y G. N. Arons; In: Carbon Adsorption Handbook, cap. 22, 819, Ann Arbor Science Pub., Ann Arbor, Mich. (1977).

[7]. J. Freeman, F.G.R. Gimblett, K.I. W. Sing. Carbon 27 (1989) 85.

[8]. A. Huidobro, A. C. Pastor Amorós, F. Rodríguez-Reinoso. Carbon 39 (2001) 389.

[9]. M.C. Blanco Lopez, A. Martınez-Alonso, J.M.D. Tascon. Carbon 38 (2000) 1177.

[10]. N. Worasuwannarak, S. Hatori, H. Nakagawa, K. Miura. Carbon 41 (2003) 933.

[11]. Y. Uraki, A. Nakatani, Y. Sano. Journal of Wood Science 47 (2001) 465.

[12]. Y.V. Basova, D.D. Edie, P.Y. Badheka, H.C. Bellam. Carbon 43 (2005) 1533.

[13]. F. Derbyshire, R. Andrews, D. Jacques, M. Jagtoyen, G. Kimber, T. Rantel. Fuel 80 (2001) 345.

[14]. J. Alcañiz-Monge, D. Cazorla-Amorós, A. Linares-Solano, A. Oya, A. Sakamoto, K. 
Hoshi. Carbon 35 (1997) 1079.

[15]. J. Alcañiz-Monge, D. Cazorla-Amorós, A. Linares-Solano, S. Yoshida, A. Oya. Carbon 32 (1994) 1277.

[16]. J. Alcañiz-Monge, D. Cazorla-Amorós, A. Linares-Solano. Fibras de Carbon: Preparacion y aplicaciones, University of Alicante Press, 1998.

[17]. S. Brunauer, P. H. Emmett, E. Teller. J. Am. Chem. Soc. 60 (1938) 309.

[18]. M. M. Dubinin; Chemistry and Physics of Carbon, Vol. 2,(Ed. P. L. Walker), Marcel Dekker, New York (1966).

[19]. P. L. Walker, F. Rusinko and L. G. Austin, Advances in Catalysis, 11, 133 (1959).

[20]. J. Alcañiz-Monge, D. Cazorla-Amorós, A. Linares-Solano, A. Oya. Anales de Química 90 (1994) 201.

[21]. I. C. Lewis. Carbon 20(1982) 519.

[22]. K. S. W. Sing, D. H. Everett, R. A. W. Haul, L. Moscou, R. A. Pierotti, J. Rouquerol, T. Siemieniewska. Pure Appl. Chem. 57 (1985) 603.

[23]. Y. Matsumara. Seikiyu Gakaishi 30 (1987) 291.

[24]. Y. Q. Fei, F. Derbyshire, M. Jagtoyen y I. Mochida; Proc. Eastern Oil Shale Symp., Lexington, KY, USA, (1993).

[25]. F. Rodríguez-Reinoso, A. Linares-Solano, Microporous structure of activated carbons as revealed by adsorption methods, in: P. Thrower (Ed.), Chemistry and Physics of Carbon, Vol. 21, Marcell Dekker, Inc., New York, 1988, pp. 2-146.

[26]. D. Cazorla-Amorós, J. Alcañiz-Monge, A. Linares-Solano. Langmuir 12 (1996) 2820.

[27]. D. Cazorla-Amorós, J. Alcañiz-Monge, M.A. de la Casa-Lillo, A. Linares-Solano. Langmuir 14 (1998) 4589.

[28]. J. Alcañiz-Monge, D. Cazorla-Amorós, A. Linares-Solano. Fuel 80 (2000) 41.

[29]. M. Zander M. Pitch characterisation for Industrial Application. In: H. Marsh, E.A. Heintz, 
F. Rodríguez-Reinoso (Eds). Introduction to Carbon technologies. University of Alicante Press. 1997 ;Chapter 8; 216.

[30]. M. Zander. Chemistry and properties of coal-tar and petroleum pitch. In: H. Marsh, F. Rodríguez-Reinoso (Eds). Sciences of Carbon Materials. University of Alicante. 2000; Chapter 6; 205-258. 
Table 1. Some properties of coal tar pitches and petroleum pitches.

\begin{tabular}{l|llllllll}
\hline \multicolumn{7}{c}{ Elemental analysis (wt \%) } & \multicolumn{5}{c}{ Insolubles (wt \%) } \\
Sample & C & H & N & S+O & H/C & TI & QI & SP (K) \\
\hline A & 92.83 & 3.50 & 0.03 & 3.64 & 0.45 & 94 & 70 & 543 \\
B & 88.20 & 3.94 & 0.02 & 3.95 & 0.53 & 87 & 56 & 548 \\
C & 93.44 & 3.34 & 0.03 & 3.23 & 0.42 & 91 & 64 & 568 \\
D & 93.37 & 3.23 & 0.03 & 3.40 & 0.42 & 92 & 67 & 583 \\
P & 94.50 & 5.31 & 0.06 & 0.02 & 0.67 & 32 & 3 & 540 \\
Q & 93.73 & 6.16 & 0.09 & 0.01 & 0.79 & 1 & 0 & 488 \\
R & 93.47 & 5.84 & 0.03 & 0.00 & 0.75 & 11 & 0 & 489 \\
V & 95.00 & 5.33 & 0.06 & 0.00 & 0.67 & 37 & 0 & 487 \\
\hline
\end{tabular}

${ }^{\mathrm{b}}$ Softening point, measured by TMA.

Table 2.- Characterisation of the porous texture of CFs and ACFs prepared from coal tar 
pitches.

\begin{tabular}{|c|c|c|c|}
\hline Sample & Vol. $\mathbf{N}_{2}(\mathrm{cc} / \mathrm{g})$ & Vol. $\mathrm{CO}_{2}(\mathrm{cc} / \mathrm{g})$ & BET $\left(\mathrm{m}^{2} / \mathrm{g}\right)$ \\
\hline CFA & -- & 0.17 & -- \\
\hline CFA30 & 0.33 & 0.28 & 800 \\
\hline CFA37 & 0.41 & 0.32 & 1010 \\
\hline CFA50 & 0.54 & 0.43 & 1280 \\
\hline CFB & -- & 0.23 & -- \\
\hline CFB32 & 0.39 & 0.41 & 955 \\
\hline CFB52 & 0.66 & 0.50 & 1555 \\
\hline CFC & -- & 0.05 & -- \\
\hline CFC28 & 0.19 & 0.18 & 446 \\
\hline CFC43 & 0.53 & 0.40 & 1300 \\
\hline CFC76 & 0.63 & 0.36 & 1470 \\
\hline CFD & -- & 0.05 & -- \\
\hline CFD25 & 0.20 & 0.15 & 483 \\
\hline CFD34 & 0.30 & 0.24 & 697 \\
\hline CFD48 & 0.51 & 0.37 & 1150 \\
\hline CFD72 & 0.63 & 0.36 & 1270 \\
\hline
\end{tabular}

Table 3.- Characterisation of the porous texture of $\mathrm{CsF}$ and ACFs produced from petroleum 
pitches.

\begin{tabular}{|c|c|c|c|}
\hline Sample & Vol. $\mathbf{N}_{2}$ (cc/g) & Vol. $\mathrm{CO}_{2}(\mathrm{cc} / \mathrm{g})$ & $\operatorname{BET}\left(\mathrm{m}^{2} / \mathrm{g}\right)$ \\
\hline CFP & --- & 0.25 & --- \\
\hline CFP14 & 0.23 & 0.33 & 520 \\
\hline CFP30 & 0.41 & 0.65 & 930 \\
\hline CFP40 & 0.61 & 0.65 & 1555 \\
\hline CFP47 & 0.79 & 0.77 & 1790 \\
\hline CFP54 & 0.85 & 0.75 & 1930 \\
\hline CFP73 & 0.98 & 0.70 & 2400 \\
\hline CFQ & 0.27 & 0.30 & 612 \\
\hline CFQ20 & 0.39 & 0.43 & 857 \\
\hline CFQ33 & 0.57 & 0.55 & 1352 \\
\hline CFQ58 & 0.78 & 0.72 & 1712 \\
\hline CFR & 0.19 & 0.23 & 396 \\
\hline CFR37 & 0.67 & 0.65 & 1353 \\
\hline CFR51 & 0.81 & 0.72 & 1680 \\
\hline CFV & 0.04 & 0.23 & 70 \\
\hline CFV21 & 0.32 & 0.48 & 725 \\
\hline CFV72 & 1.09 & 0.75 & 2410 \\
\hline CFV90 & 1.18 & 0.73 & 2759 \\
\hline A15 & 0.57 & 0.33 & 1270 \\
\hline A20 & 0.91 & 0.52 & 2100 \\
\hline
\end{tabular}




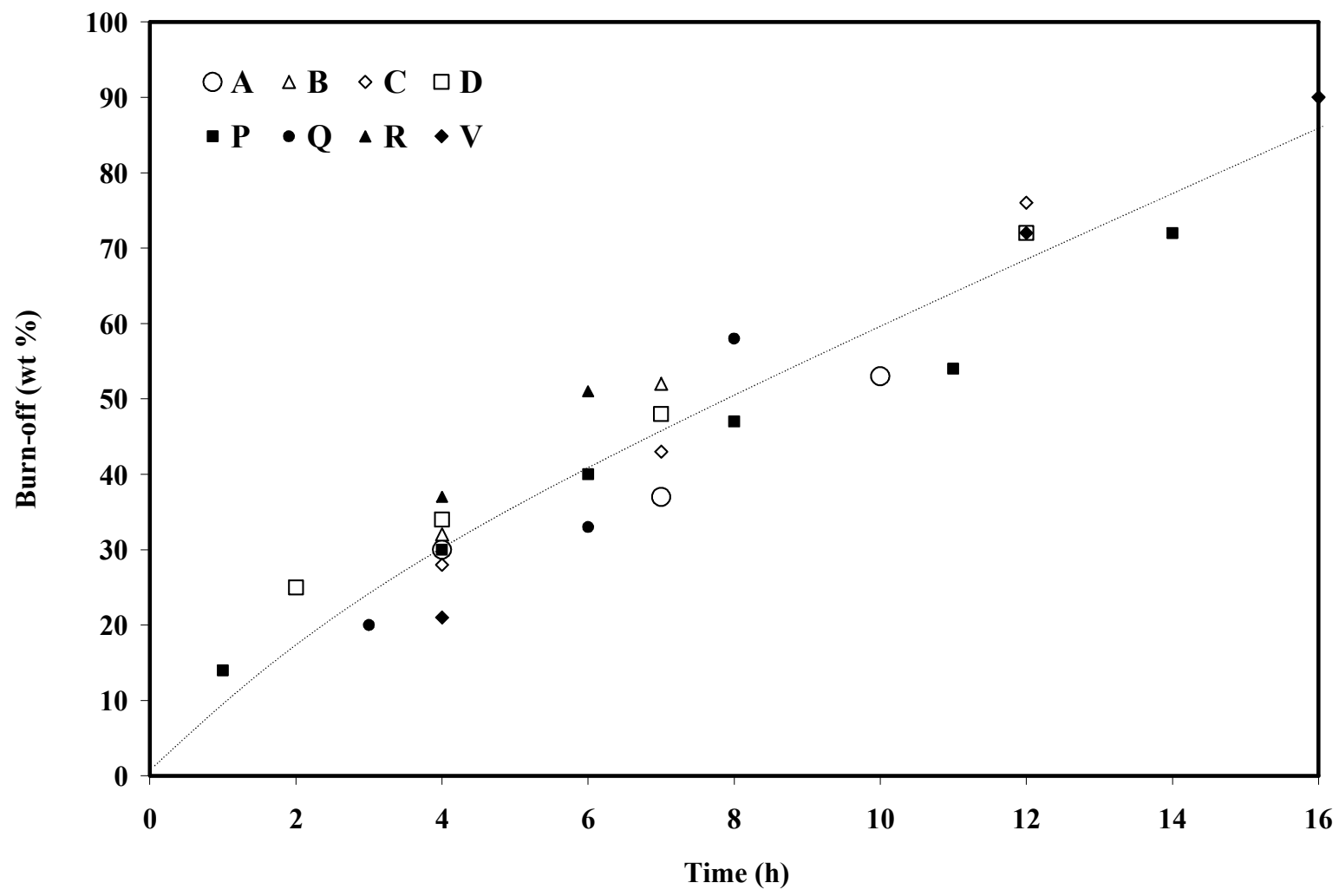

Figure 1.- Evolution of burn-off versus time for the different CFs prepared. 


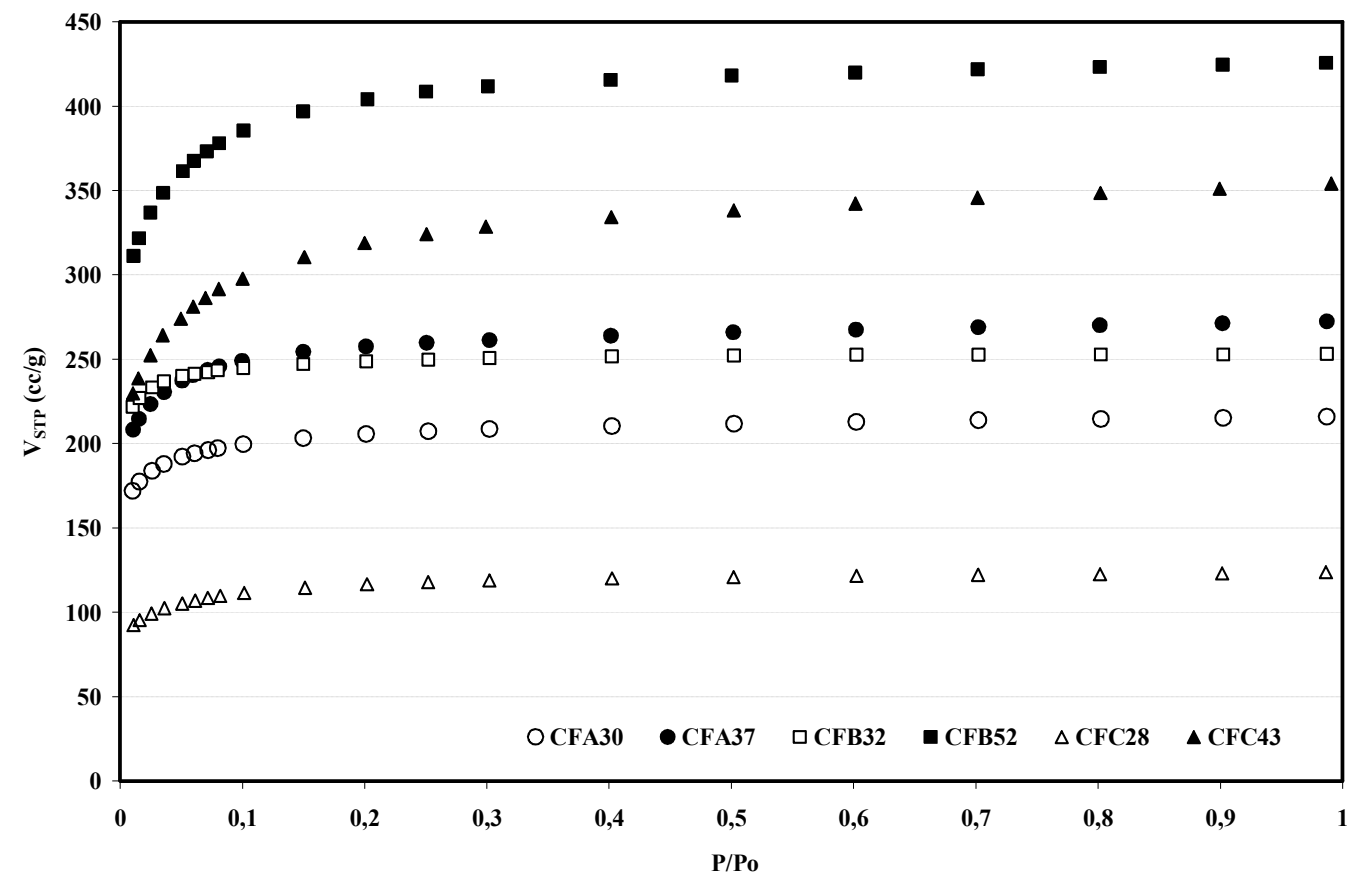

Figure 2.- $\mathrm{N}_{2}$ adsorption isotherms at $77 \mathrm{~K}$ for the series of ACFs prepared from coal tar pitches (A, B and C). 


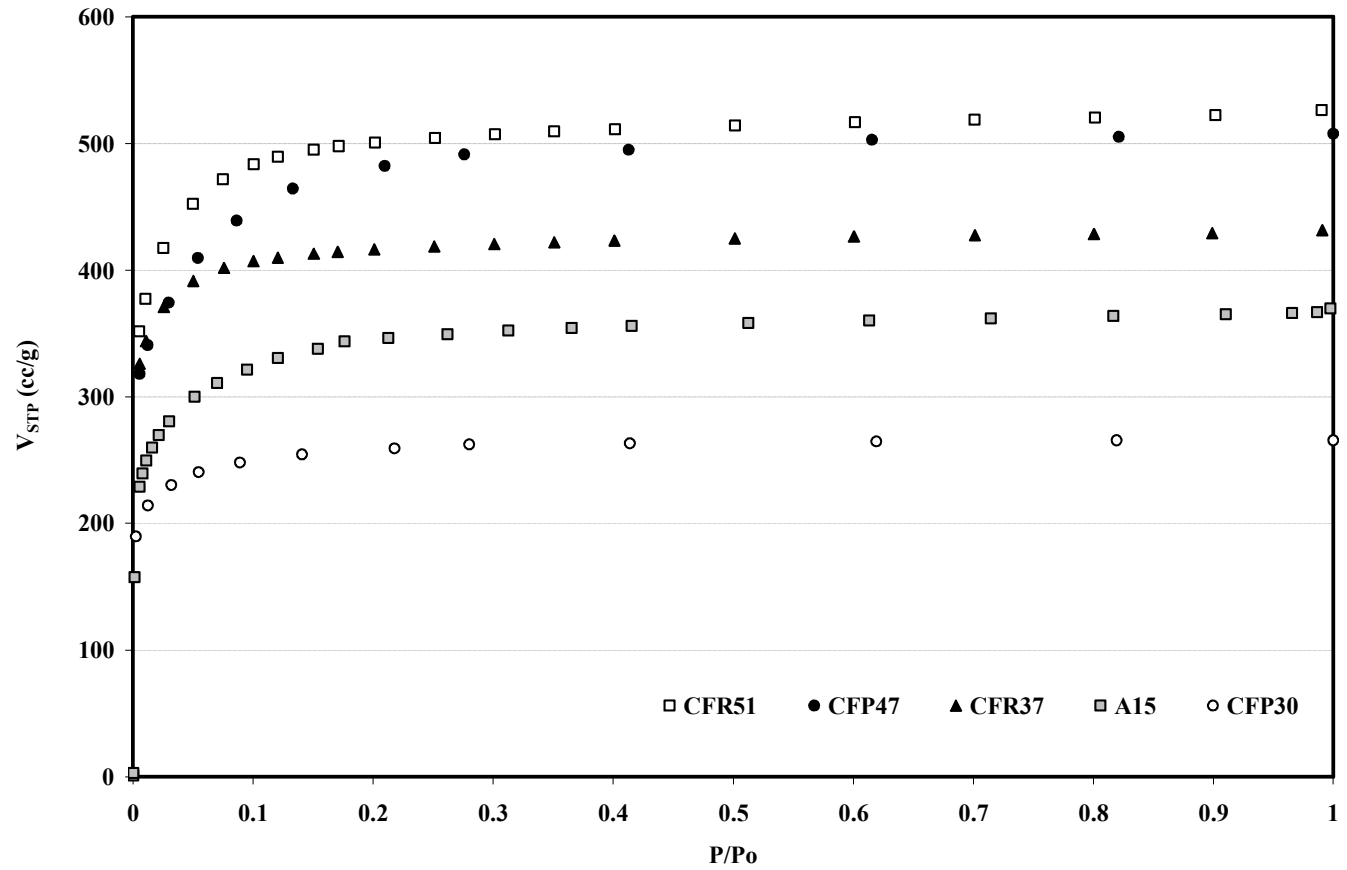

Figure 3.- $\mathrm{N}_{2}$ adsorption isotherms at $77 \mathrm{~K}$ for the series of ACFs prepared from petroleum pitches (P and R), and a commercial ACF (A15). 


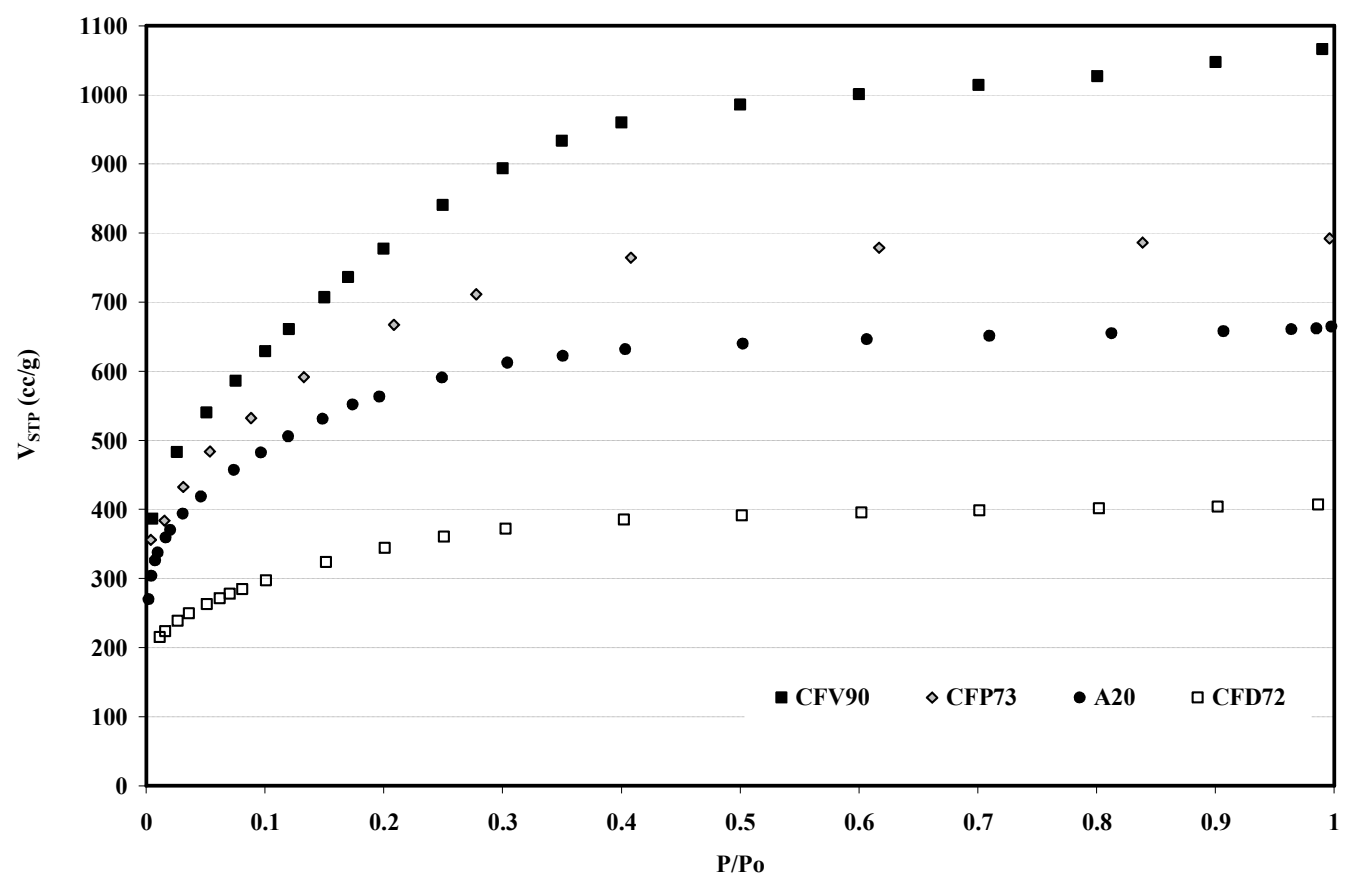

Figure 4.- $\mathrm{N}_{2}$ adsorption isotherms at $77 \mathrm{~K}$ for highly activated ACFs prepared from petroleum pitches (V and P), coal tar pitches (D), and a commercial ACF (A20). 

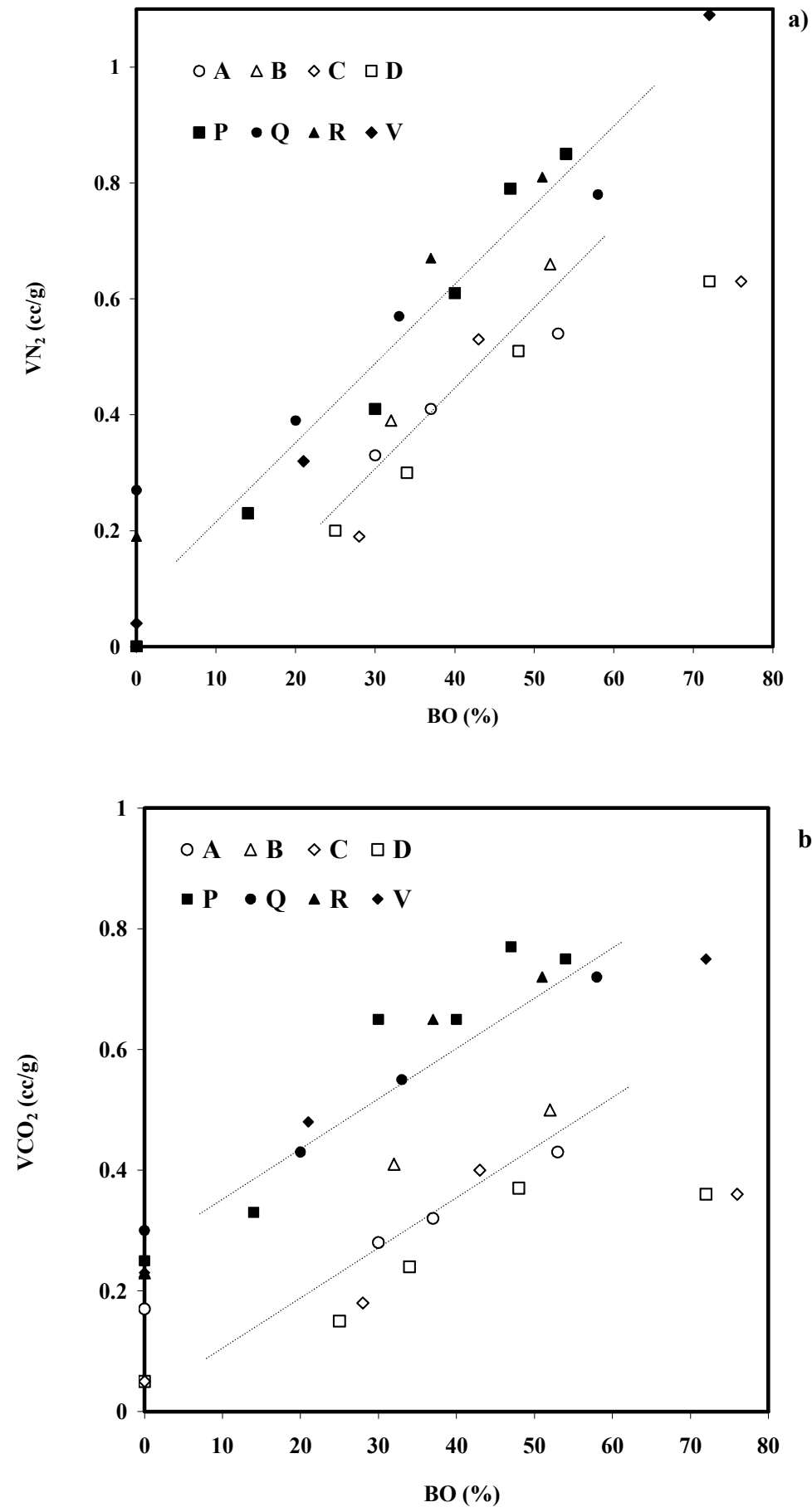

b)

Figure 5.- Micropore volume evolution obtained a) from the $\mathrm{N}_{2}$ adsorption and b) from $\mathrm{CO}_{2}$ adsorption versus burn-off (wt \%) for the ACFs prepared. 


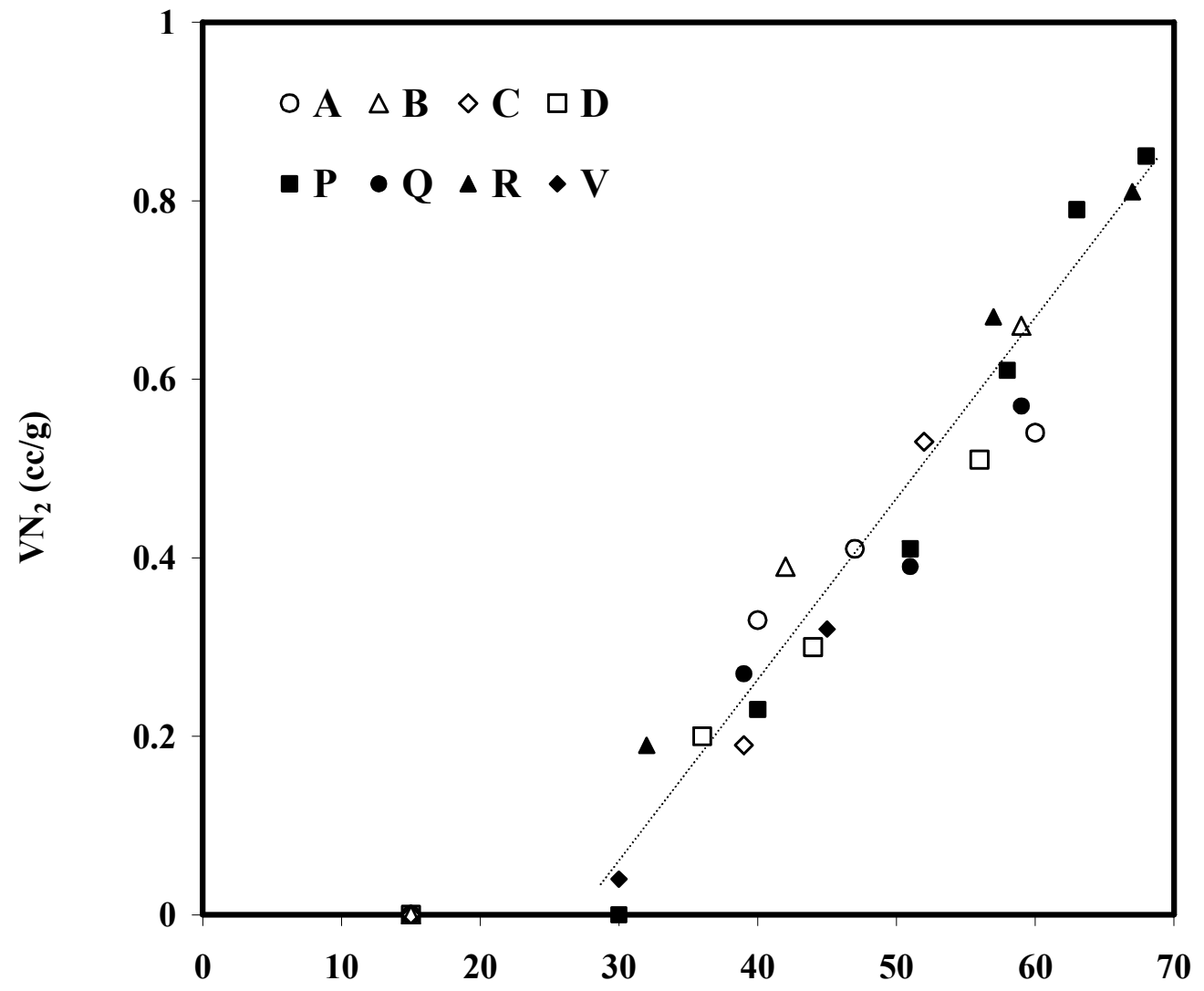

Comprehensive weight loss $(\%)$

Figure 6.- Micropore Volume evolution assessed by $\mathrm{N}_{2}$ adsorption versus the comprehensive weight loss percentage for ACFs. The comprehensive weight loss percentage is referred to the original quantity of pitch fibres. 


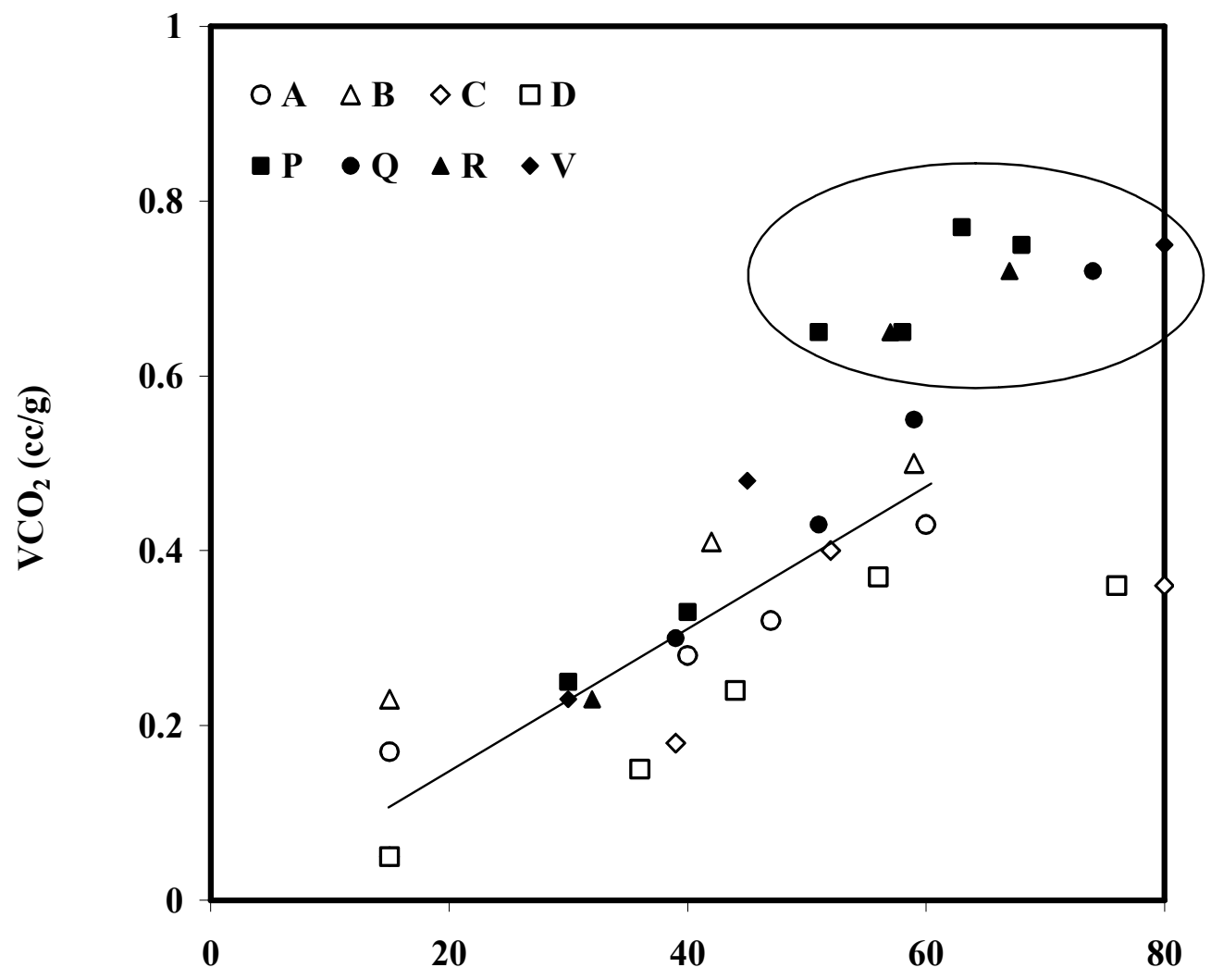

Comprehensive weight loss (\%)

Fgure 7.- Micropore volume evolution assessed by $\mathrm{CO}_{2}$ adsorption versus the comprehensive weight loss percentage for ACFs. 